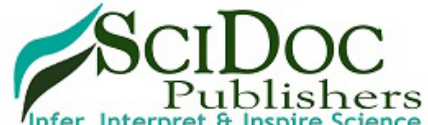

\author{
International Journal of Dentistry and Oral Science (IJDOS) \\ ISSN: 2377-8075
}

\title{
Assessment Of Frequency and Gender Distribution of Full Veneer Crowns among Root Canal Treated Maxillary Anterior Teeth in An Institutional Setup - A Retrospective Study
}

Research Article

Roghith Kannan ${ }^{1}$, Adimulapu Hima Sandeep² ${ }^{2}$, Revathi Duraisamy ${ }^{3}$

${ }^{1}$ Saveetha Dental College and Hospitals, Saveetha Institute of Medical and Technical Sciences, Saveetha University, Chennai, India.

${ }^{2}$ Senior Lecturer, Department of Conservative Dentistry and Endodontics, Saveetha Dental College and Hospitals, Saveetha Institute of Medical and Technical Sciences, Saveetha University, Chennai, India.

${ }^{3}$ Senior Lecturer, Dental College and Hospitals, Saveetha Dental College and Hospitals, Saveetha Institute of Medical and Technical Sciences, Saveetha University, Chennai, India.

\section{Abstract}

The selection of the best restoration for an endodontically treated tooth in the aesthetic zone depends on strength and the ability to recreate the form, function, and aesthetics of the natural tooth. The longevity of endodontically involved teeth has been greatly enhanced by continuous developments made in endodontic therapy and restorative procedures. The main objective of this study is to know the frequency of root canal treated maxillary anteriors treated with full veneer crowns. The current study is an institutional based retrospective study performed by reviewing 2066 cases that had undergone root canal therapy in relation to maxillary anteriors. A total of 386 subjects who underwent root canal treatment in relation to maxillary anteriors under 30 years of age were selected for the study from the total of 2066 subjects. Patients reported to the clinic other than maxillary anterior root canal treatment and medically compromised patients were excluded. Once the data was obtained, it was statistically analyzed using SPSS by IBM version 20. From this current study, it was found that, out of 386 patients, $68.39 \%$ (264) males and $31.61 \%$ (112) females have undergone root canal treatment. Maxillary central incisors were most commonly restored with full veneer crowns compared to other teeth. The frequency of teeth that had received full veneer crowns was $50.03 \%$ (271). Chi square test was done to associate between gender, tooth groups and practice of post endodontic crown. No statistically significant association was found between gender, tooth groups and the practice of post endodontic crowns. Root canal treated maxillary anterior teeth without sound tooth structure should be managed with full coverage restorations.

Keywords: Crowns; Maxillary Anteriors; Root Canal Treatment.

\section{Introduction}

Restoration of endodontically treated teeth (ETT) is often considered as being distinct from root canal treatment. However both are inseparable in planning execution and prognosis. Root canal treatment involves the removal of necrotic and infected tissues followed by the provision of a well condensed obturation to prevent further microbial proliferation within the canal system [1]. The potential ingress of microbes into the canal system will compromise the outcome of the treatment. Hence the coronal seal is important in the final stages of the root canal treatment. Achievement of this goal is confirmed by the shape and size of this space, as mechanical shaping alone is insufficient and chemically active fluids are difficult to deliver effectively to the canal terminus. It has therefore been argued that the canal should be prepared for larger dimensions [2].

In restorative dentistry, the non vital tooth and its restoration have been extensively studied from both structural and esthetic aspects [3]. Root filled teeth are structurally and aesthetically compromised due to the loss of tissue at crown and root levels which leads to significant biomechanical changes resulting in high incidence of fractures [4]. Studies show that fracture of root filled teeth and, in consequence, the risk of tooth loss are considerably

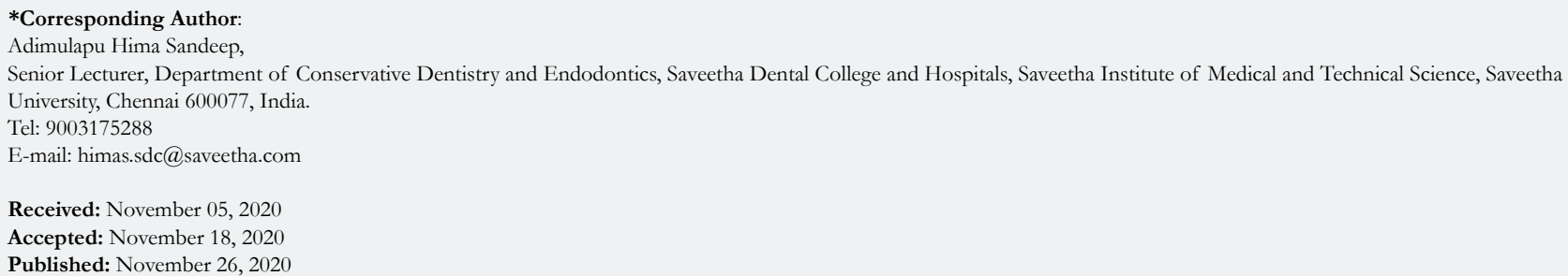

Citation: Roghith Kannan, Adimulapu Hima Sandeep, Revathi Duraiswamy. Assessment Of Frequency and Gender Distribution of Full Veneer Crowns among Root Canal Treated Maxillary Anterior Teeth in An Institutional Setup - A Retrospective Study. Int J Dentistry Oral Sci. 2019;S10:02:0017:90-94. http://dx.doi.org/10.19070/2377-8075-SI02-0100017

Copyright: Adimulapu Hima Sandeep 2019 . This is an open-access article distributed under the terms of the Creative Commons Attribution License, which permits unrestricted use, distribution and reproduction in any medium, provided the original author and source are credited. 
higher than that of the teeth with vital pulps [5]. The endodontically treated teeth for anterior teeth traditionally were restored with post and core as the foundation.

For many years the use of Porcelain fused metal (PFM) crowns have represented the most widely used technique in maxillary anterior teeth. This popularity may have attributed to the clinical longevity and accepted aesthetics of restoration [6]. With the development of the new adhesive technology in the last few decades clinicians can maintain superior aesthetics when restoring maxillary anterior endodontically treated teeth. All ceramic restoration of endodontically treated teeth in maxillary anteriors with GPF showed excellent results with regard to aesthetics and retention [7].

One of the most important factors influencing the success of restoration is the amount of remaining tooth structure [8]. When crowns are considered the need for a ferrule is mandatory for a more predictable restoration. It must be remembered that endodontically treated teeth have an endodontic access cavity and any further preparation for an extra coronal restoration may have a very thin band of dentin which may be prone to fracture. Minimal preparations are ideal to preserve tooth structure [9]. The aim of this study was to assess the frequency and gender distribution of full veneer crowns among root canal treated maxillary anterior teeth in an institutional setup.

\section{Materials and Methods}

\section{Study Setting}

The current study is an institutional based retrospective study performed at a private dental college.

\section{Ethical approval}

The necessary approvals were obtained from the Institutional Ethical committee - SDC/SIHEC/2020/DIASDATA/0619-0320.

\section{Data Collection and Tabulation}

All the case records and treatment records were obtained after verifying 86,000 case sheets and the data collected was cross veri- fied by an examiner to avoid any missing case records. A total of 2066 case sheets were found with root canal treatment done in relation to maxillary anteriors. Out of 2066 subjects, 386 subjects who underwent root canal treatment in relation to maxillary anteriors under 30 years of age were chosen carefully verifying the data and history. All the data collected was formatted and tabulated using Microsoft Excel (Version - 2020). The dependent variable was root canal treated maxillary anteriors under 30 years of age.

\section{Inclusion criteria}

The Inclusion criteria included patients undergoing root canal treatment in relation to maxillary anteriors under 30 years of age.

\section{Exclusion criteria}

The exclusion criteria was missing or incomplete data and it also eliminated cases that were not approved by the concerned faculty in the hospital.

\section{Statistical analysis}

The statistical analysis was performed using IBM SPSS (Version - 24). Chi square test was done, to associate between gender and post endodontic crown and tooth number and post endodontic crown for prognosis of the root canal treated teeth.

\section{Results and Discussion}

In the present study which included 386 patients, 68.39\% (264) males and $31.61 \%$ (122) females have undergone root canal treatment (Figure 1). Out of 541 teeth which had undergone root canal treatment, full veneer crowns had been fabricated and inserted in 271 maxillary anteriors (50.04\%) and the remaining 270 (49.91\%) maxillary anteriors did not receive full veneer crowns (Figure 2). The most common teeth for root canal treatment was found to be 11 and 21 with $(31.42 \%)$ followed by $12(16.27 \%)$, $22(13.12 \%), 23(4.44 \%)$, and the least being 13 (3.33\%) (Figure). $33.16 \%$ of males and $14.51 \%$ of females had received crowns, $35.23 \%$ of males and $17.10 \%$ of females did not receive crowns (Figure 4) No significant association was seen between gender and practice of full veneer crowns. Chi-square test was performed

Figure 1. Bar graph depicts the frequency of males and females who had undergone root canal treatment in maxillary anteriors. $X$ axis represents the gender of patients and $Y$ axis shows the number of patients who underwent root canal treatment. The results show the highest number subjected to root canal therapy was seen among males(blue) $68.39 \%$ compared to females(red) $31.61 \%$.

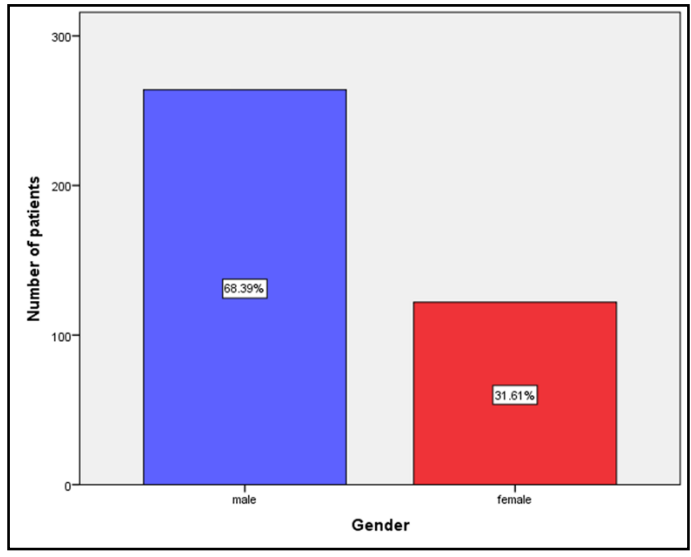


Figure 2. Bar graph depicts the frequency of incidence of post endodontic crown in patients who had undergone root canal treatment in maxillary anteriors. The $\mathrm{X}$ axis represents the post endodontic crown placement status and $\mathrm{Y}$ axis represents the number of teeth. The results show that the incidence of post endodontic crown in maxillary anteriors was more $(50.09 \%)$ when compared to teeth without a post endodontic crown $(49.91 \%)$.

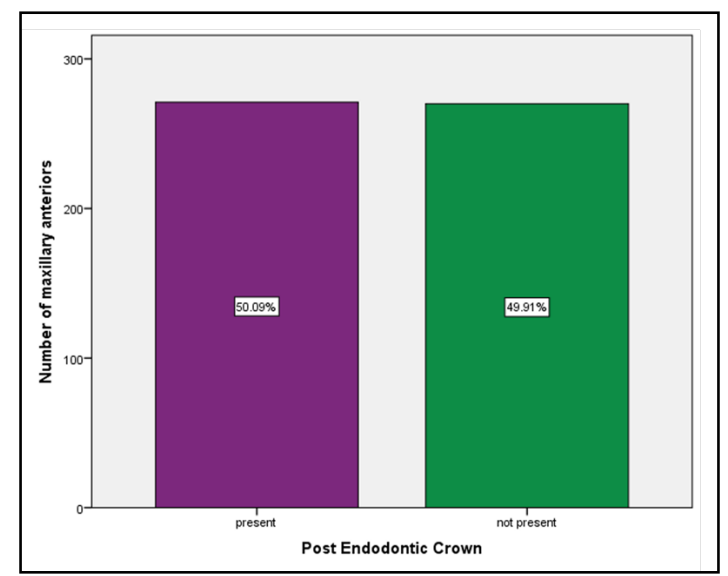

Figure 3. Bar graph depicts the frequency of various teeth involved in root canal treatment in maxillary anteriors. $\mathrm{X}$ axis shows the various teeth number and $Y$ axis shows the number of teeth which had undergone root canal treatment. The results show the highest incidence of root canal treatment was seen in 11 and 21 with $31.42 \%$ compared to other teeth.

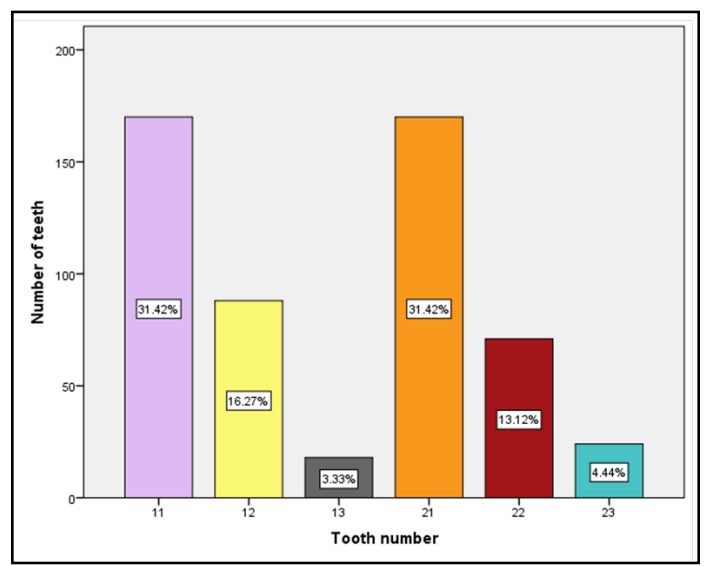

Figure 4. Bar graph depicts the association of gender and incidence of post endodontic crown in maxillary anteriors. The $\mathrm{X}$ axis represents the gender and $\mathrm{Y}$ axis shows the number of patients with presence or absence of post endodontic crowns. Chi-square test was performed and no statistically significant association was noted. (Pearson chi square value: 0.223 ; df: 1 ; p-value: $0.637>0.05)$. However, the frequency of males $(33.16 \%)$ who received full veneer crowns as well as those who did not receive full veneer crowns $(35.23 \%)$ was more than that of females.

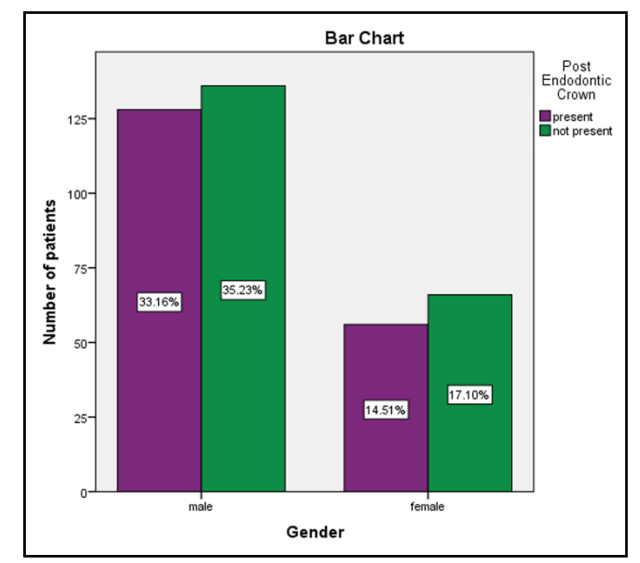

and was found to be statistically not significant $(\mathrm{p}=0.637 ; \mathrm{p}>$ 0.05). $17.19 \%$ of root canal treated teeth in relation to 21 had received crowns, which was followed by $14.23 \%$ in $11,8.69 \%$ in $12,6.47 \%$ in $22,2.22 \%$ in 23 and the least being $1.29 \%$ in 13 . $17.19 \%$ of root canal treated teeth in relation to 11 and 21 did not receive crowns, which was followed by $7.58 \%$ in $12,6.65 \%$ in $22,2.22 \%$ in 23 and the least being $2.03 \%$ in 13 . Results show the highest incidence of presence of full veneer crowns was seen in $21(17.19 \%)$ compared to other teeth (Figure 5) Chi-square test was performed and was found to be statistically not significant $(\mathrm{p}$ $=0.504 ; \mathrm{p}>0.05)$.

Restoration of root filled teeth has an important role in clinical practice. From the results obtained in this study, $68.39 \%$ of males 
Figure 5. Bar graph depicts the association between various teeth with and without post endodontic crown in root canal treated maxillary anteriors. The $\mathrm{X}$ axis represents the various teeth involved in root canal treatment and $\mathrm{Y}$ axis shows the number of teeth with and without post endodontic crown. Chi-square test was performed and no statistically significant association was noted. (Pearson chi square value: 4.322 ; df:5; p-value: $0.504>0.05$ ). However, the frequency of post endodontic full veneer restoration in $21(17.19 \%)$ was more compared to other tooth groups.

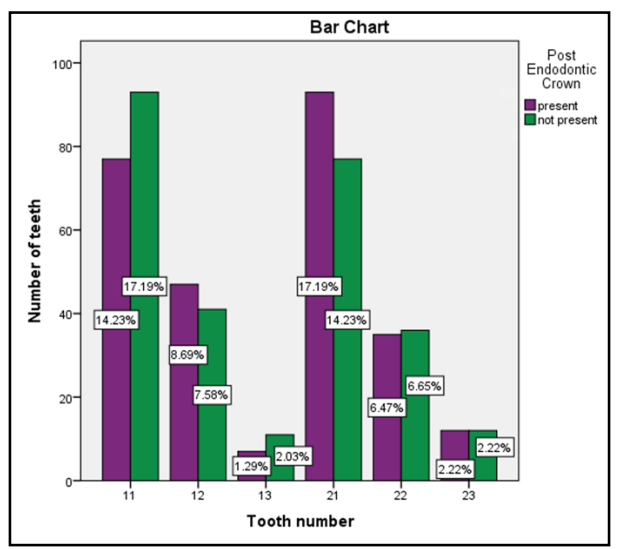

and $31.61 \%$ of females had undergone root canal treatment in relation to maxillary anteriors under 30 years of age of which full veneer crowns had been fabricated and inserted in 271 maxillary anteriors (50.09\%) and the remaining 270 (49.91\%) maxillary anteriors did not receive full veneer crowns. The most common teeth for root canal treatment was found to be 11 and 21 with $(31.42 \%)$. The highest incidence for the presence of full veneer crowns was seen in $21(17.19 \%)$. It was also seen that males $(33.16 \%)$ had the highest incidence for undergoing full veneer crowns.

In anterior teeth posts are required when there is minimal coronal tooth structure present. Posts can provide resistance from against tipping or lateral forces and can contribute to the retention form [10]. The use of ceramic crowns is said to build integrity and provide maximum resistance to withstand forces and improve the quality of the restoration as it helps in enhancing the esthetics [11]. In anterior endodontically treated teeth that are intact except for the access opening, direct restorations without further removal of tooth structure are preferred. The decision of placing a full crown should be decided depending on the remaining natural tooth structure and aesthetics.

It must be remembered that endodontically treated teeth have an endodontic access cavity and any further preparation tends to weaken the remaining natural tooth structure [12]. One of the main causes for fracture of endodontic treated teeth is an incomplete instrumentation or filling of all the root canals. In recent years the use of crowns have become very popular. The introduction of improved all-ceramic systems makes it possible to achieve optimal esthetics allied with the necessary mechanical properties to withstand functional stresses which may prevent the fracture of the endodontically treated teeth [4].

The endodontically treated teeth at the aesthetic zone can be restored with composite for long and temporary restorations, while all ceramic crowns can be used to replace the PFM restorations because of their better physical, mechanical and excellent biocompatibility [13]. In recent literature, it has been stated that high esthetic results and similar mechanical properties have been achieved in hard dental tissues through the restoration of endodontically treated teeth with esthetic fiber-reinforced posts [14]. Treatment planning must consider the possibility of restoring the tooth and its implications and must require a careful analysis of residual tooth structure at both the coronal and root levels. It is also important to maintain good oral health and hygiene to prevent the entry of further diseases. Previously our team had conducted numerous clinical trials [15-17], in vitro studies [18-22] and surveyed $[23,24]$ and reviewed various aspects of endodontics and conservative dentistry over the past five years [25-29]. Now we are focusing on retrospective studies, the idea for which has stemmed from the current interest in our community.

\section{Conclusion}

Within the limitations of the study, the prevalence of root canal treated maxillary anteriors with post endodontic crowns was $50.037 \%$, in which maxillary central incisors were most commonly restored with full veneer crowns compared to other teeth. No statistically significant association was found between gender and the practice of post endodontic crowns. In this study males had undergone more post endodontic crowns than females in the age group of 18 to 30 years. Endodontically treated teeth without sound tooth structure should be managed with full coverage restoration.

\section{Author Contribution}

Roghith Kannan carried out the retrospective study, collection and analysis of data and drafted the manuscript. Dr Adimulapu Hima Sandeep designed the study and participated in data analysis verification and drafting the manuscript. Dr Revathi D aided in supervision and appraisal of the manuscript.

\section{Acknowledgements}

We thank Saveetha Dental College and Hospitals, Chennai for giving access to the retrospective data.

\section{References}

[1]. Tronstad L, Asbjørnsen K, Døving L, Pedersen I, Eriksen HM. Influence of coronal restorations on the periapical health of endodontically treated teeth. Endod Dent Traumatol. 2000 Oct;16(5):218-21. PMID: 11202885.

[2]. Gutmann JL. The dentin-root complex: anatomic and biologic consid- 
erations in restoring endodontically treated teeth. J Prosthet Dent. 1992 Apr;67(4):458-67. PMID: 1507126.

[3]. Zalkind M, Hochman N. Esthetic considerations in restoring endodontically treated teeth with posts and cores. J Prosthet Dent. 1998 Jun;79(6):702-5. PMID: 9627901

[4]. Maccari PC, Conceição EN, Nunes MF. Fracture resistance of endodontically treated teeth restored with three different prefabricated esthetic posts. J Esthet Restor Dent. 2003;15(1):25-30. PMID: 12638770.

[5]. Sedgley CM, Messer HH. Are endodontically treated teeth more brittle? J Endod. 1992 Jul;18(7):332-5. PMID: 1402595.

[6]. Trushkowsky RD. Esthetic and functional consideration in restoring endodontically treated teeth. Dent Clin North Am. 2011 Apr;55(2):403-10. PMID: 21474001.

[7]. Meyenberg KH, Lüthy H, Schärer P. Zirconia posts: a new all-ceramic concept for nonvital abutment teeth. J Esthet Dent. 1995;7(2):73-80. PMID: 8593239 .

[8]. Abbott PV. Assessing restored teeth with pulp and periapical diseases for the presence of cracks, caries and marginal breakdown. Aust Dent J. 2004 Mar;49(1):33-9. PMID: 15104132

[9]. Kishen A. Mechanisms and risk factors for fracture predilection in endodontically treated teeth. Endodontic topics. 2006 Mar;13(1):57-83.

[10]. Khaldi F. Post placement and restoration of endodontically treated teeth: a review. International Journal of Medicine in Developing Countries 2020; 534-537.

[11]. Vichi A, Ferrari M, Davidson CL. Influence of ceramic and cement thickness on the masking of various types of opaque posts. J Prosthet Dent. 2000 Apr;83(4):412-7. PMID: 10756290.

[12]. Schwartz RS, Robbins JW. Post placement and restoration of endodontically treated teeth: a literature review. J Endod. 2004 May;30(5):289-301. PMID: 15107639 .

[13]. Deger S, Akgüngör G, Caniklioglu B. An alternative method for fabricating a custom-made metal post with a ceramic core. Dent Traumatol. 2005 Jun;21(3):179-82. PMID: 15876332

[14]. Azer SS, Ayash GM, Johnston WM, Khalil MF, Rosenstiel SF. Effect of esthetic core shades on the final color of IPS Empress all-ceramic crowns. J Prosthet Dent. 2006 Dec;96(6):397-401. PMID: 17174656.

[15]. Ramamoorthi S, Nivedhitha MS, Divyanand MJ. Comparative evaluation of postoperative pain after using endodontic needle and EndoActivator during root canal irrigation: A randomised controlled trial. Aust Endod J. 2015 Aug;41(2):78-87. PMID: 25195661.

[16]. Hussainy SN, Nasim I, Thomas T, Ranjan M. Clinical performance of resinmodified glass ionomer cement, flowable composite, and polyacid-modified resin composite in noncarious cervical lesions: One-year follow-up. J Conserv Dent. 2018 Sep-Oct;21(5):510-515. PMID: 30294112.
[17]. Janani K, Palanivelu A, Sandhya R. Diagnostic accuracy of dental pulse oximeter with customized sensor holder, thermal test and electric pulp test for the evaluation of pulp vitality: an in vivo study. Brazilian Dental Science. 2020 Jan 31; 23(1):8-p.

[18]. Ramanathan S, Solete P. Cone-beam Computed Tomography Evaluation of Root Canal Preparation using Various Rotary Instruments: An in vitro Study. J Contemp Dent Pract. 2015 Nov 1;16(11):869-72. PMID: 26718293.

[19]. Siddique R, Sureshbabu NM, Somasundaram J, Jacob B, Selvam D. Qualitative and quantitative analysis of precipitate formation following interaction of chlorhexidine with sodium hypochlorite, neem, and tulsi. J Consery Dent. 2019 Jan-Feb;22(1):40-47. PMID: 30820081.

[20]. Rajendran R, Kunjusankaran RN, Sandhya R, Anilkumar A, Santhosh R, Patil SR. Comparative Evaluation of Remineralizing Potential of a Paste Containing Bioactive Glass and a Topical Cream Containing Casein Phosphopeptide-Amorphous Calcium Phosphate: An in Vitro Study. Pesquisa Brasileira em Odontopediatria e Clínica Integrada. 2019;19.

[21]. Teja KV, Ramesh S, Priya V. Regulation of matrix metalloproteinase-3 gene expression in inflammation: A molecular study. J Conserv Dent. 2018 NovDec;21(6):592-596. PMID: 30546201.

[22]. Nandakumar M, Nasim I. Comparative evaluation of grape seed and cranberry extracts in preventing enamel erosion: An optical emission spectrometric analysis. J Conserv Dent. 2018 Sep-Oct;21(5):516-520. PMID: 30294113.

[23]. Jose J, Subbaiyan H. Different Treatment Modalities followed by Dental Practitioners for Ellis Class 2 Fracture-A Questionnaire-based Survey. The Open Dentistry Journal. 2020 Feb 18;14(1).

[24]. Manohar MP, Sharma S. A survey of the knowledge, attitude, and awareness about the principal choice of intracanal medicaments among the general dental practitioners and nonendodontic specialists. Indian J Dent Res. 2018 Nov-Dec;29(6):716-720. PMID: 30588997.

[25]. Rajakeerthi R, Ms N. Natural Product as the Storage medium for an avulsed tooth-A Systematic Review. Cumhuriyet Dental Journal. 2019;22(2):24956.

[26]. Kumar D, Antony S. Calcified Canal and Negotiation-A Review. Research Journal of Pharmacy and Technology. 2018;11(8):3727-30.

[27]. Ravinthar K. Recent advancements in laminates and veneers in dentistry. Research Journal of Pharmacy and Technology. 2018;11(2):785-7.

[28]. Noor S. Chlorhexidine: Its properties and effects. Research Journal of Pharmacy and Technology. 2016;9(10):1755-60.

[29]. Janani K, Palanivelu A, Sandhya R. Diagnostic accuracy of dental pulse oximeter with customized sensor holder, thermal test and electric pulp test for the evaluation of pulp vitality: an in vivo study. Brazilian Dental Science. 2020 Jan 31;23(1):8-p. 